\title{
Theofilos
}

\section{Intelligent Design and Natural Theology}

\author{
Steinar Thorvaldsen \\ Professor of Information Science, Department of Education \\ The Arctic University of Norway, Norway \\ steinar.thorvaldsen@uit.no
}

\begin{abstract}
Natural Theology is an attempt to provide arguments for the existence of God based on reason and ordinary experience of nature. It became quite popular with both orthodox Christians and Deists between about 1650 and 1850, inspiring much of the scientific fieldwork done during that period. However, Darwin's theory of evolution brought about a temporary decline of this Christian apologetic tradition.

Intelligent Design is a relatively new scientific research program that investigates the effects of intelligent sources, and challenges basic parts of contemporary Darwinism. Fred Hoyle first issued the ideas of Intelligent Design in modern times when he discovered the unique energy level of the carbon atom in the 1950s. On Copernicus's 500th birthday in 1973, Brandon Carter presented the discovery that the fundamental constants of physics are fine-tuned to precise values for life permittance. In the 1990s, Michael Behe and others presented arguments for Intelligent Design in molecular biology, and irreducibly complex biochemical machines in living cells.

In this paper, we briefly present Intelligent Design and discuss its possible application within a revitalized version of Natural Theology. The paper is mainly written from a scientific perspective.
\end{abstract}

Keywords: Fine-tuning, Design, Darwinism, Molecular machines, Complexity

\section{Introduction}

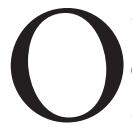

ur subject is part of a wider discussion about the relationship of science to religion. In most parts of the world, both science and religion have substantial influence on people's lives and ways of thinking. The impact of science and technology is even so penetrating that we hardly notice it.

According to Ian Barbour, there are four ways of relating science and religion: ${ }^{1}$

\section{Conflict}

2. Independence

3. Interaction

4. Integration

These models interpret the relationship quite differently, but none of them regards religion as something irrelevant for society. Barbour's work is an attempt to revisit the interface between science and religion, and constitutes a conceptual investigation of the differences, meeting points, and parallels between them. $\mathrm{He}$ 
aims to move beyond conflict and independence to greater dialogue, and the interaction model provides one way for making that move. There are a number of arguments for this. First, human experience does not divide itself into discrete experiences, since reality is handled as a whole. Second, for Christians, God is the creator of all that is, and if God is the source of the whole of the universe, then Christians should seek explanations that do not separate religious faith from the natural world. Thirdly, the need for a response to the environmental crisis demands a strong theology of nature, grounded in biblical faith commitments and engaged with scientific knowledge of the world. Given those demands, interaction between science and religion is a much-needed contribution to an educated discourse.

Integration is the 4th model for thinking about relating science and religion. In addition to interaction, integration also focuses on the relationships between theological doctrines and particular scientific theories. According to Barbour, the classic Natural theology and Barbour's own Theology of nature are two examples of the integration between science and religion. Whereas the traditional Natural theology mainly looks to design in nature as supportive of God's existence, the Theology of nature has a broader scope and develops theories and doctrines that are heavily informed by theories of science. ${ }^{2}$ Such an approach is more radical, and may include revisions of some traditional doctrines on creation, providence or human nature, in the light of current science. Barbour has built his 'Theology of nature,' on Darwinian theory and the naturalistic philosophy that undergirds it. $\mathrm{He}$ presupposes that the Darwinian mechanism is the means by which biological complexity has emerged within nature.

A large amount of academic literature on these topics has appeared since the 1970s. However, it is difficult to evaluate how successful it has been. The general public still seems convinced that science and religion are in conflict with each other. This is largely the result of quite aggressive atheists such as Richard Dawkins and others, ${ }^{3}$ whose works are translated worldwide and have influenced public opinion. Even academics often limit their knowledge to these sources.

In addition, theological institutions only sparsely focus on the interaction between science and religion. Especially in systematic theology, discussions concerning the scientific worldview and the possibility of divine action are often more or less ignored. If theologians are not taking the dialogue seriously, who is?

In this paper, we first introduce Natural Theology and Intelligent Design. A more extensive elaboration and discussion of the scientific arguments for detecting design may be found in our recent statistical paper 'Using statistical methods to model the fine-tuning of molecular machines and systems.' ${ }^{4}$ In the second part of the present paper, we discuss the application of the design arguments within a revitalized version of Natural Theology.

\section{Natural Theology (NT)}

In the first period in the history of modern science, the declaration of purposiveness in the observed nature was not regarded as an embarrassment, but rather an accepted fact. ${ }^{5}$ Pioneers like Johannes Kepler, Galileo Galilei and Isaac Newton were all motivated by, and promoted their innovative research as, 'reading the book of nature'. ${ }^{6}$ Modern science grew 
up in Europe around the beginning of the 17 th century, and Christianity had the function of being some of the soil from which it grew.

In spite of some unfortunate tension, Christian theology can still claim to have helped birth the basic beliefs and impulses that gave rise to modern empirical science. A number of historians and sociologists have come to view modern science itself as the historical product of Christianity. It is hard to get much further from the conflict thesis than this. ${ }^{7}$ There exists a profound causal connection between Christianity and early modern science. This is an important historical fact for Christian apologetics. ${ }^{8}$

Natural theology was in this period quite important for the whole science and religion dialogue. The phrase 'natural theology' can have several meanings that in general substantiate an intellectual resonance between the Christian worldview and the natural world. Thus, the world that we see and experience around us is believed to have a deeper transcendence, which lies beyond it, but in some ways are embedded in the world that we observe.

In the year 1802 William Paley published his famous book Natural Theology: or, Evidences of the Existence and Attributes of the Deity; Collected from the Appearances of Nature. ${ }^{9}$ The main message of this book was that all nature speaks of the Designer behind it. Paley's argument is constructed around a series of examples, including finding a watch, comparing the eye to a telescope, and the existence of finely adapted mechanical structures in animals: from the intricacy of the bird's wing to the complexity of the eye, since living structures are far beyond the power of physical processes operating by natural laws, they must be the wise contrivance of a Creator. In consequence, the existence of the structured world and life around us, proved the existence of a designer or God behind them.

The theological interpretation of Payley's thesis became known as Natural theology and was widely applied in theological circles almost everywhere where thinking Christianity existed. The book was used for many years as a textbook in British universities as a basis for examination for undergraduates. Natural Theology became quite popular with both orthodox Christians and Deists. It prospered greatly as an apologetic tool, particularly in England, between about 1650 and 1850 , inspiring much of the fieldwork done in biology during that period. Collecting butterflies, beetles, flowers and ferns etc., also became a popular outdoor hobby, all with a sense of attaining a closer understanding of nature's master Designer.

Within German biology, a coherent body of theory based on a teleological approach was also worked out. The history of pre-Darwinian German biology in the nineteenth century is acknowledged as very active in the growth of empirical knowledge, which includes the beginning of modern embryology, paleontology, physiology and organic chemistry. One main impetus for the development of biological thought in Germany came from an idealistic philosophy of nature known as romantische Naturphilosophie. ${ }^{10}$ Here the central issue was the problem of causality in biology, and Timothy Lenoir labels this approach a 'theory of limited evolution'. 11 The romantic natural philosophy embraced at least the aesthetic dimension of natural theology. ${ }^{12}$

The problem with the arguments in Natural Theology is, of course, that they can be turned head around. Thus for 
every instance where the natural theologian finds reason to sing God's praises, the natural anti-theologian finds reason to lament nature's cruelty. Darwin, for instance, thought there was 'too much misery in the world' to find support in Natural Theology:

I cannot persuade myself that a beneficent and omnipotent God would have designedly created the Ichneumonidae [a parasitoid wasp] with the express intention of their feeding within the living bodies of Caterpillars [a larvae], or that a cat should play with mice. ${ }^{13}$

Other examples he pointed to included 'ants making slaves' and 'the young cuckoo ejecting its foster-brother.' We may note that Darwin's intellectual struggles with the problem of evil were plainly $p h i$ losophical and theological in nature they had not proceeded from his science. However, he did not give the problems any further elaboration. Darwin apparently understood that the ultimate framework for a basic interpretation of nature could not be scientific, but was philosophical and rooted in an individual's conception of the relationship between the natural world and religion. Hence, the presence of natural suffering accorded well with his theory of natural selection, rather than with purpose and design in the optimistic setting of contemporary Victorian theology of a world in gentle harmony.

With Darwin, a grand unifying science of life was set forth by the principle of natural selection. The new Darwinian Theory reduced some of the conceptual difficulties to scientific progress in biology, like vitalism and some speculative teleological thinking. On the other hand, the theologians could no longer base their teaching confidently on the thesis that
'The havens declares the glory of God, and the firmament shows his handiwork'. ${ }^{14}$

Darwin changed the direction of the discussions through his explanation of biology as a product of natural processes. This mechanistic point of view carries with it the naturalistic aims of modern science. Natural Theology changed focus to natural philosophy, later this was replaced by natural history. Because they held to a naturalistic definition of science, Darwinian explanations seemed more sensible to most scientists. Payley's theory was more or less destroyed and substituted by the new Darwinian 'plots and stories'15. Eventually, Darwin's theory brought about the decline of the Christian apologetic tradition in science, in spite of some academic attempts to rescue the project of Natural Theology. ${ }^{16}$ Lynn Barber ${ }^{17}$ documents very well the close relationship between the declining public interest in natural philosophy and the corresponding ascendancy of the theory of evolution.

\section{Intelligent Design (ID)}

The fundamental idea behind ID is that events, objects, and structures in the world can exhibit features that reliably signal the effects of intelligence. Disciplines as diverse as semiotics, archeology, cryptography, forensic science, and the search for extraterrestrial intelligence thus all fall within ID. ID begins with features of the world that are inherently resistant to naturalistic explanation given the available natural resources - not merely features of the world that for now lack a known natural-cause explanation, but rather for which natural causes are in principle incapable of providing an explanation. Next, ID notes that in our normal 
experience, when objects whose causal story we know show such features, then an intelligence was definitively involved in the object's causal history.

The very term intelligence comes from the Latin words 'inter' (a preposition denoting 'between') and 'lego' (a verb denoting to 'choose' or 'select'). Hence, strictly speaking intelligence refers to the power of discerning and the ability to select. Yet unlike natural selection, which operates without intentions or goals, typically when we think of an intelligence as choosing or selecting, it is with a goal or purpose in mind. We could therefore define intelligence as the capacity for rational or purposive choice.

The textbook definition of ID reads: 'The study of patterns in nature that are best explained as the product of intelligence'. ${ }^{18}$ Intelligent means nothing more than being the result of an intelligent source, and does not presume optimal design. 'Intelligent' in 'intelligent design' simply refers to intelligent sources, irrespective of skill, mastery, or cleverness.

For Del Ratzsch, design needs another concept, namely counterflow, which 'refers to things running contrary to what, in the relevant sense, would (or might) have occurred had nature operated freely.' 19 Furthermore, 'an artifact is anything embodying counterflow.'20 That does not mean, of course, that any violation of natural law (counterflow) can be defined as design, but we typically recognize artifactuality and designedness through recognizing indications of counterflow in results, processes or initial conditions: 'we recognize such counterflow against the background of and in contrast with our understanding of the normal flows of nature.'21

ID has gained a good deal of interest and influence in recent years, mainly in the USA, by both creating public attention and triggering vigorous discussions in the intellectual and scientific world. The term is often considered controversial, and many prefer to use the term design alone, since usually we think of design as the result of intelligence, and hence the adjective is redundant. However, Intelligent Design is the original historic term that Professor William Whewell at Trinity College, Cambridge, coined in a scientific context as far back as in 1833.22 The term was applied by Darwin, and also by Hoyle $^{23}$ when he reintroduced the idea within modern science in his 1982 Omni Lecture at the Royal Institution, London. In this paper we use both the short and long notion.

\section{Quantum physics}

The famous astronomer Sir Fred Hoyle did the first basic ID-discovery of our time as early as in the 1950 s, ${ }^{24}$ when he predicted that the carbon core has a unique state with a specific energy level which is precisely adapted to the basic fusion process for carbon creation. This result was one of the most important breakthroughs in modern astrophysics, and the so-called Hoyle state of the carbon atom has become a cornerstone for state-of- the-art nuclear theory. He described his discovery like this:
Would you not say to yourself, 'Some super-calculating intellect must have designed the properties of the carbon atom, otherwise the chance of my finding such an atom through the blind forces of nature would be utterly minuscule.'... The numbers one calculates from the facts seem to me to so overwhel- ming as to put this conclusion almost beyond question. ${ }^{25}$

All known life in this universe is based on the element carbon, which is formed in 
the nuclear processes that occurred as previous stars ended their lives. The calculations he made in time revealed a finetuning of the universe. Hoyle had started his research career as an atheist, but this scientific discovery shook his atheism fundamentally. ${ }^{26}$

\section{General physics}

To our surprise, it turns out that many of the parameters necessary for life to exist in our universe must fall within very narrow margins, or the universe would either not exist or not be able to support life. The astrophysicist Brandon Carter was the first to name and employ the term Anthropic Principle in his important contribution to the 1973 conference in Poland honoring Copernicus's 500th birthday. He had worked with a kind of counterfactual analysis of cosmology by asking the question: Suppose the laws of physics had been a bit different from what they actually are, what would the consequences be?27 In his lecture, Carter derived the Anthropic Principle in reaction to the old Copernican Principle, which states that humans do not occupy a privileged position in the universe. As Carter said on Copernicus's birthday:

Although our situation is not necessarily central, it is inevitably privileged to some extent. 28

The chances that the universe should be life permitting are so infinitesimal as to be incomprehensible and incalculable. Many studies have been accomplished since then. Luke Barnes published a good review paper on the fine-tuning of the universe in $2012^{29}$ and Lewis \& Barnes wrote an up-to-date book in 2016.30

It is hard to give a definitive answer to the number of fine tuning parameters. Based on the items discussed in Barrow and Tiplers' classic book ${ }^{31}$ there are about 100, and The Royal Astronomer Martin Rees lists six dimensionless constants that give overall fine-tuning to the universe. ${ }^{32}$ The finely tuned universe is like a panel that controls the parameters of the universe with about 100 knobs that can be set to certain values. If you turn any knob just a little to the right or to the left, the result is either a universe that is inhospitable to life or no universe at all. If the Big Bang had been just slightly stronger or weaker, matter would not have condensed, and life never would have existed. The odds against our universe developing were 'enormous' - and yet here we are, a point redolent with religious implications, as expressed by Brian Schmidt at the Australian National University:

Like a Bach fugue, the Universe has a beautiful elegance about it, governed by laws whose mathematical precision is meted out to the metronome of time. These equations of physics are finely balanced, with the constants of nature that underpin the equations tuned to values that allows our remarkable Universe to exist in a form where we, humanity, can study it. A slight change to these constants, and poof, in a puff of gedanken experimentation, we have a cosmos where atoms cease to be, or where planets are unable to form. We seem to truly be fortunate to be part of Our Universe. 33

What Brian Schmidt refers to as a 'gedanken experiment' (thought experiment), is often called 'multiuniverses', i.e. an enormous supply of universes and each one a little different. This hypothesis is not backed up with any empirical support, and Nobel laurate in physics Charles Townes rejects this speculative idea as a 'pretty fantastic postulate'. Instead, Townes thinks this 'fine-tuning' of the universe 
points to intelligent design:

Intelligent design, as one sees it from a scientific point of view, seems to be quite real. This is a very special universe: it's remarkable that it came out just this way. 34

One nice recent study shows that if the mass of the quarks that make up protons and neutrons were changed by just a few percent, then the process that makes carbon as stars die would be altered in such a way that there would not be sufficient carbon in the universe for life. The masses of the lightest sub-atomic quarks have the precise value that is required for carbon to form and for life to exist. 35 The fact that the conditions for life fall into such a narrow range, plus the many incredible initial conditions and constants in physics that give rise to the needed building blocks of life, constitute the fine-tuning of the bio-friendly universe. Fig. 1 is a simple illustration.

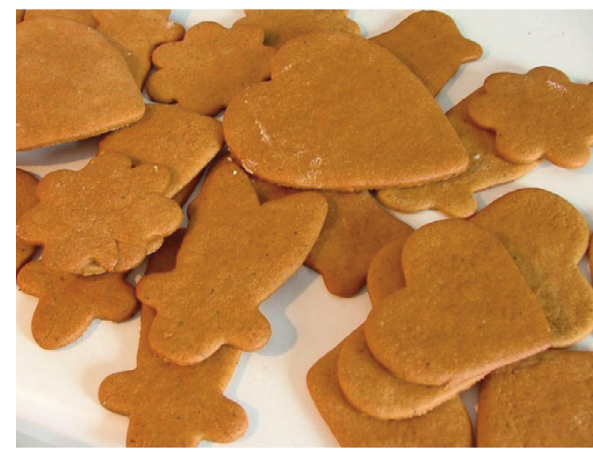

Figure 1: Illustration of fine-tuning suggested by a schoolchild: Bake several batches of pepper cookies, each time varying one ingredient, oven-baking temperature or time up or down by a minor amount. Call it a 'Cookie Universe' and successfully demonstrated the fine-tuning principle by the taste of the cookies. From www.arn.org

\section{Molecular machines}

One of the surprising discoveries of modern biology has been that the cell operates in a manner similar to modern technology, while biological information is organized similar to plain text. Words and terms like sequence code, and information, proofreading, and machine have proven very useful in describing and understanding molecular biology. ${ }^{36}$ Living forms exhibit structures and functions that can best be understood as nano-level engineering. In 1998 Bruce Alberts, president of the National Academy of Sciences, published an important paper preparing the next generation of molecular biologists: 'The Cell as a Collection of Protein Machines'. ${ }^{37}$ In the same manner, the ID research program also highlights the designed structure of life in nature against Darwinian natural selection and gradualism, and in the 1990s, Michael Behe and others argued for ID in molecular biology and irreducibly complex biochemical machines in living cells. ${ }^{38}$ Some parts of complex designed objects are exceedingly important and useful and do affect the function of their mechanism. The intelligence of the designed product and its smart processes can be outlined through the vital and functional parts of living organisms. In 'Darwin's Black Box' Behe exemplifies the systems that he called irreducible complexity configured as a remarkable teamwork of several interacting proteins.

However, Behe does not ignore the role of the laws of nature. Biology allows for changes and evolutionary modifications. Evolution is there, ID is there, and they are consistent with one-another. The laws of nature can organize matter and force it to change. Behe's point is that there are some, 'irreducibly complex' systems that are very unlikely to be produced by the laws of nature, and this is sufficient for his argument to work: 
If a biological structure can be explained in terms of those natural laws [reproduction, mutation and natural selection] then we cannot conclude that it was [intelligently] designed... however, I have shown why many biochemical systems cannot be built up by natural selection working on mutations: no direct, gradual route exist to these irreducible complex systems, and the laws of chemistry work strongly against the undirected development of the biochemical systems that make molecules such as AMP. 3940

Then, even if the natural laws work against the development of these 'irreducible complexities', they exist. Putting 'intelligent' in front of 'design' ensures that the design he is talking about is not merely apparent but actual; actual in the sense that the design is a strong synergy in principle irreducible to natural causes. These structures are biological examples of nano-engineering that surpass anything human engineers have created. Fig. 2 shows a high-resolution image.

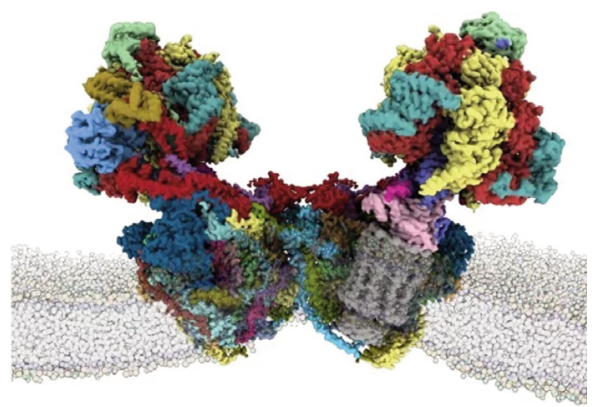

Figure 2: Researchers at Stockholm University solved the structure of a mitochondrial ATP synthase. ATP synthase is a molecular machine that catalyzes conversion of chemical energy of cells. The high resolution allowed identification of 29 different protein subunits. Credit: A. Müblpeip.

From www.scilifelab.se

\section{Proteins}

The basic building blocks of life are proteins, long chain-like molecules consisting of varied combinations of 20 different amino acids. Complex biochemical machines are usually composed of many proteins, each folded together and configured in a unique 3D structure dependent upon the exact sequence of the amino acids within the chain. Proteins employ a wide variety of folds to perform their biological function, and each protein has a highly specified shape with some minor variations. An important question is to obtain an estimate of the overall prevalence of sequences adopting functional folds, i.e. the right folded structure, with the correct dynamics and a precise active site for its specific function. Douglas Axe worked on this question at the famous Medical Research Council Centre in Cambridge. The experiments he performed showed a prevalence between 1 in $10^{50}$ to 1 in $10^{74}$ of signature-consistent sequences forming a working domainsized fold of 150 amino acids. ${ }^{41}$ Hence, functional proteins require highly extraordinary sequences. Though proteins tolerate a range of possible amino acids at some positions in the sequence, a random process producing amino-acid chains of this length would stumble onto a functional protein only about one in every $10^{50}$ to $10^{74}$ attempts. This empirical result is analog to our previous ID inferences from fine-tuned physics.

In his recent book, Undeniable, Axe also elaborates on the massive improbabilities of anything like functional proteins arising by natural selection. The search space turns out to be too impossibly vast for blind selection to have even a slight chance of success. The contrasting view is innovations based on ingenuity, 
cleverness and intelligence. An element of this is what Axe calls 'functional coherence', which always involves hierarchical planning, hence is a product of design. He concludes: 'Functional coherence makes accidental invention fantastically improbable and therefore physically impossible.' ${ }^{42}$ Fig. 3 shows an example of a functional protein.

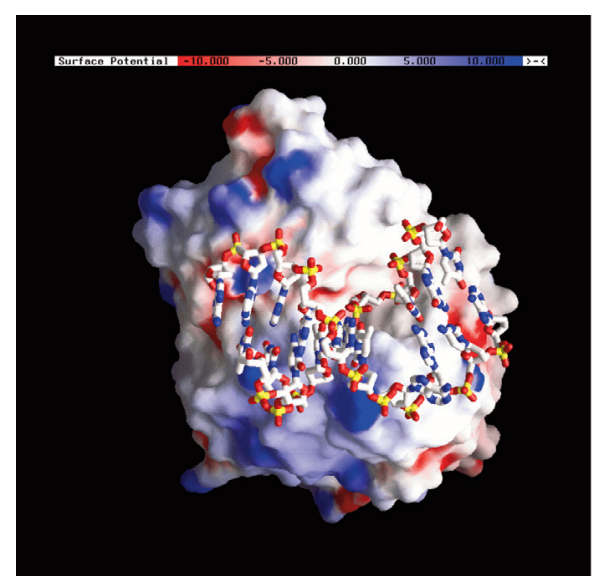

Figure 3: The enzyme Uracil-DNA-glycosylase (UNG) is a fold of 233 amino acids and repairs errors in DNA. UNG is an important intracellular, monomeric enzyme that recognizes and removes errors occurring when DNA is copied. The figure shows how DNA is attached to the enzyme.

\section{Measuring design}

Science is to a large extend devoted to measuring quantities, and much effort has been devoted to detecting design and finding a general information measure. Del Ratzsch ${ }^{43}$ has expressed doubt on the prospects of recognizing designedness through secondary marks, because in the context of identifiable artifacts, that artifactuality by itself automatically establishes some of the crucial conditions for design.

In order to infer design, an object must be both complex and specified. The latest version of an information measure published by Dembski et al. is named Algorithmic Specified Complexity (ASC). ${ }^{44}$ ASC incorporates both Shannon and Kolmogorov complexity measures, and measures the degree to which an event is improbable and follows a pattern. Kolmogorov complexity is related to compression of data (and hence patterns), but suffers from the property of being unknowable as it has no general method to compute it. However, it is possible to give upper bounds for the Kolmogorov complexity, and consequently ASC can be bounded without being computed exactly. ASC is based on context and is measured in bits. The authors have applied this promising method to natural language, random noise, folding proteins, images etc. 45 This is an area of research, and recently George Montanez published a general method of detecting design that incorporates randomness and specificity, and unifies many previous attempts. ${ }^{46}$

\section{ID's relation to NT}

ID argues that the effect of a design inference can be deduced within the limits of explanatory options, not from identifying an external cause. We may detect that our house has been cleaned, without knowing who did it. To identify an ultimate cause we need additional details, but ID is not primarily in the business of telling causal stories. Dembski argues for the distinction like this: ${ }^{47}$

Although a design inference is often the occasion for inferring an intelligent agent, as a pattern of inference the design inference is not tied to any doctrine of intelligent agency. The design inference focuses on features of any event that bar it from being attributed to chance, not on the causal story underlying 
the event. To be sure there is a connection between the design inference and intelligent agency. This connection, however, is not part of the logical structure of the design inference. Certain events are properly attributed to chance, certain events are not. The design inference marks the difference, yet without prejudging the underlying causal story.

Hence, Dembski does not commit the category mistake of failing to distinguish causal agency from the underlying mechanism. There are natural laws and there are ID, yet none of these is enough to conclude that there is a lawgiver or designer God. Inferences to design should not require that we have a candidate for the role of a designer. That will be an additional interpretation that has to be done in a wider context.

Clearly, ID provides ready meals for NT, and many ID-scientists are Christians and believe on independent theological grounds in a designer God. However, some also avoid making any ontological commitments about a designer, and are perfectly content investigating design in nature. 48 ID may for the time being be operated mainly by Christians. But Christians do not own it - it is not even owned by theists. ID is not a form of NT. The aims are substantially different.

The designer that eventually emerges from ID-theory is an intelligence capable of originating the complexity and specificity that we find throughout the universe, especially in biological systems. The designer of ID is not the God of any particular philosophical reflection or the God of any particular religion, but merely an intelligent source that is capable of initiating certain features of the natural world. Persons with theological commitments can co-opt this designer and identify this designer with the object of their faith. However, this inference is strictly free as far as the actual science of ID is concerned. The point is to see if design offers fresh scientific insights, not to establish the existence of the designer. ID therefore makes an epistemological rather than ontological point.

\section{Discussion}

We have presented four central observations from contemporary science; two from 'hardware' physics, and two from 'software' biology. The framework of ID depends on the concept of probability theory, information, computer science, molecular biology, and the philosophy of science. Exponents of ID claim that it is a valid scientific field because it builds on the same prima causa premise used in all other areas of science. They observe information systems in the cells of living organisms and question the source of that information. The main issue that motivates ID is a concern for good science, and ID aims to adhere to the same standards of rational investigation as other scientific and philosophical enterprises, and is subject to the same methods of evaluation and critique. We will discuss the ID-arguments above in this context. Can they be formulated as rigorous scientific arguments?

William Dembski has noted that the fine-tuning argument for our universe is not a strict statistical argument, since it involves features that need to be in place before the universe can be said to exist and operate. ${ }^{49}$ And there is no way of assigning a probability distribution as reference associated with the universe in that early stage. Probabilities for the initial formation of the universe are by their nature independent of known processes operating in our present universe. 
Dembski regards the fine-tuning argument as suggestive, as pointers to underlying ID. We may describe this statistical inference as abductive reasoning or inference to the best explanation. ${ }^{50}$ An explanation is a story about an event that has occurred, and explanatory inferences play a central role in both ordinary life and scientific thinking. Computer science, expert systems and artificial intelligence research frequently employs it. Abduction is the procedure of choosing the hypothesis or theory that best explains the available data. This process yields a plausible conclusion but does not positively verify it. The plausible result is relatively likely to be true, compared to competing hypotheses, given our background knowledge. In the case of fine-tuning of our cosmos, ID is considered to be a better explanation than a set of multi-universes that lacks any empirical evidence. ${ }^{51}$

The constants of nature are universal properties wherever matter exists, and the unique resonance state of the carbon atom discovered by Hoyle is a consequence of the fine-tuned properties of the 12 particles in the atomic core. Science is still working on details of this very complicated 12-body problem, and by utilizing powerful supercomputers, a team of scientists have calculated the properties of the Hoyle state from the fundamental constants and forces of nature. ${ }^{52}$ The process of production runs by the laws of nuclear physics, and the carbon product displays its additional fine-tuning property at the atomic level.

A Behe-system of irreducible complexity is composed of several non-arbitrarily, well-matched, interacting modules that contribute to a basic function, wherein the removal of any one of the modules causes the system to effectively cease functioning. The system cannot be sub- stantially simplified and yet preserve function. Such systems pose a serious challenge to a Darwinian account of evolution, since irreducibly complex systems have no direct series of selectable intermediates. This logic has been severely criticized, and extensive arguments have been written about whether or not Darwinian evolution can plausibly explain irreducibly complex systems. ${ }^{53}$

Irreducible complexity does not mean that irreducibly complex systems are logically impossible to evolve. One cannot definitively rule out the possibility of an indirect, circuitous route. As the complexity of an interacting system increases, however, the likelihood of such an indirect route drops quickly. Hence, Darwinian explanations of irreducibly complex systems are improbable.

Ultimately, this is a question that has to be studied experimentally and by computer simulations. The flagellum that bacteria use to swim, and the blood-clotting cascade, are two well-studied cases. Both consist of dozens of protein parts, and despite more than twenty years of effort, no Darwinian pathway has been found. ${ }^{54}$ In addition, computer models have not falsified Behe's concept of irreducible complexity. ${ }^{55}$ William Dembski has suggested a statistical model, inspired by the Drake equation from astrobiology, that may be useful to analyze probabilities of Behe-systems, and he found very low values. ${ }^{56}$

The paper by Douglas Axe we referred to earlier is an empirical study of a single protein that typically would be involved as one of the constituting parts of a Behesystem. Protein sequence space may look like a limitless desert of maladjusted sequences with only a few oases of working sequences, as outlined by the experiments by Axe. Yet another study exami- 
nes the probability of finding ATP binding proteins from a random sample of sequence space regardless of the fold. ${ }^{57}$ The authors estimated a probability of 1 in $10^{11}$ to find an ATP binding protein, suggesting a higher probability than found by Axe. Recently Kozulic and Leisola $^{58}$ made careful analyses of these results, and concluded that even with very conservative conditions, the probability of finding ATP binding activity that would function in a cell, would be less than 1 in 1032. Estimates like these depend on various factors, including the length of the proteins considered, and indicate that while the probability of finding a functional protein in sequence space can vary broadly it commonly remains far beyond the reach of Darwinian processes. ${ }^{59}$ Some authors have even suggested that the original amino acid repertoire consisted of only four or five amino acids, to reduce the gigantic sequence space, and 'rule out the big number game'.60 However, this would need another type of genetic code, something considered highly speculative.

The protein argument is based on a standard statistical estimation of prevalence, i.e. the proportion of a population who have a specific characteristic or pattern (working proteins). Such studies are commonly performed by examining a randomly selected sample from the entire population. The proteins of life are found to be specific kinds of events with low probability.

\section{ID as science?}

The idea that nature is a closed system of natural causes, and that natural causes provide a complete account of everything that occurs in nature, is deeply rooted in natural science. Natural causes, as the scientific community usually understands them, are causes that operate according to deterministic and non-deterministic laws that can be characterized in terms of chance, necessity, or their combination (cf. Jacques Monod's Chance and Necessity). However, a fundamental element of ID is that the observed features, even when conditioned by a physical system that embodies it, cannot be reduced to such a natural account without remainder. Within the ID literature, that remainder is typically identified as some form of complexity: 'functional complexity' (Marcel Schutzenberger), 'irreducible complexity' (Michael Behe), and 'specified complexity' (William Dembski). It is not complexity alone that is the basis for the claims about ID, it is rather a duality, a particular complexity of dual nature that we have discovered in biology.

Humans have a powerful intuitive understanding of design that precedes modern science. Our common intuitions invariably begin with recognizing pattern and design. The problem has been that our intuitions about design have been unrefined and pre-theoretical. There is no surprise that ID is as controversial as it highlights a gap between common culture, which is largely committed to ID reasoning, and scientific culture, which largely rejects it in favor of Darwinian naturalism. Darwinism has been well developed and extensively advertised within science. ID is turning the tables on this disparity by promising to place the rough and pre-theoretical intuitions on a firm rational foundation, and thus promote a supplementary add-on to Darwinian Theory and the competing claims of Darwinism.

One main methodological constraint that often is used to keep ID outside of natural sciences is the framework of methodological naturalism. According to metho- 
dological naturalism, in categorizing any natural phenomenon, the natural sciences are properly permitted to invoke only natural processes, to the exclusion of ID descriptions. Methodological naturalism is a regulative framework that purports to keep science on the straight and narrow by limiting science to natural causes. The widespread philosophical opinion conceives methodological naturalism as an intrinsic and self-imposed limitation of science, as a 'ground rule' and a basic element of the scientific enterprise by definition. ${ }^{61}$

Reconciling science and religion on the basis of methodological naturalism happens at the expense of philosophical and scientific integrity, and it is therefore misguided. It leaves the public with the impression that evolution by natural selection appears to win the scientific debate only because ID with its prearrangements or configurations, is already carefully excluded from the outset. ${ }^{62}$ One cost that goes along with methodological naturalism is that one cannot claim that science, at least when it theorizes about origins, purports to tell us the truth about the world, but only that science gives us the best naturalistic story. This moves finding truth about several important questions of origins outside the domain of science, to terra incognito, philosophy or theology.

Steve Fuller and others are critical of claims that science has to be 'methodologically naturalistic.' 63 If an intelligence actually played a crucial role in the origin of biological complexity, practicing a strict methodological naturalism would actively hinder the progress of science. A more open position described as pragmatic naturalism (cf. Ludwig Wittgenstein) simply wants to understand nature and does not care what entities are involved to facilitate that understanding, as long as they prove conceptually fruitful. Pragmatic naturalism places no restraint on Intelligent Design. ${ }^{64}$

The main methodic difference between ID supporters and the opposition is the adherence to methodological naturalism. Many scientists require a purely natural explanation for all effects, while proponents of ID are open to intelligent causation in a metaphysical context for the empirical results we observe, and do not rule out such ideas a priori. The preprogramming of an ID-system is due to the presence of great amounts of information in the finely tuned initial conditions. In science, modelling a system frequently amounts to handling an initial value problem. This is a well-known scientific approach.

Thomas Kuhn openly acknowledged that metaphysics and values were an integral part of science and scientific change, because these were inherent to any usual paradigm. ${ }^{65}$ Metaphysics should not be looked upon with lack of respect, but as a necessary part of doing science. Furthermore, he acknowledged that we do not have a direct, neutral knowledge of reality, but that all of our perceptions are partly colored by our presuppositions, assumptions, and values, so that strong claims to objective knowledge needed to be treated with caution. While the inspiration of work in ID and its 'context of discovery' may be religious, this needs not to be any bar to its counting as scientific in its successive 'context of justification'. ID may have some theological inspiration and implications, but that does not sort it out as a theological enterprise.

\section{Some interpretations of ID}

There may be no single interpretation of ID that is generally valid to all times and 


\begin{tabular}{|l|l|l|l|}
\hline Empirical data & Method & Category (scientific) & $\begin{array}{l}\text { Interpretation } \\
\text { (Nat. Theology) }\end{array}$ \\
\hline Fine-tuned physics & Abductive inference & $\begin{array}{l}\text { Design } \\
\text { (or multiverse) }\end{array}$ & God's creation \\
\hline Carbon resonance & Physics deduction & Design & God's creation \\
\hline Proteins & Statistical estimation & Design & Sod's creation \\
\hline Molecular motors & $\begin{array}{l}\text { Statistical estimation } \\
\text { (preliminary) }\end{array}$ & (Design) & \\
\hline
\end{tabular}

Table 1. A hierarchical overview of scientific data, methods, and category of the ID-arguments in this paper. Methods at each line are based on the existence of data and material one line higher up in the table. The scientific parts are shown in the three columns to the left. Interpretations within the framework of Natural Theology are added in the 4th column.

places. Such interpretation must be handled in social and philosophic context. How we understand nature and rationality is in principle framework-dependent.

Within the strict framework of methodological naturalism, the interpretation is obliged to stay with the dialectics of chance and necessity, as Franklin Harold states it in one of his books. ${ }^{66}$ In the same book, he also admits that there are no detailed Darwinian accounts for these biological systems, 'only a variety of wishful speculations'. Others may denote this part of science as an enigma.

However, within a theistic or Christian framework, we may answer the apologetic question by saying that the Christian framework is clearly consistent with the observations at hand. It will be a very difficult task to argue that the only way to make sense of a certain observation is by appealing to the Christian framework, and it is a more manageable task to argue that certain scientific observations make better sense of the phenomenon within the Christian framework than without. One can make a cumulative case by combining different observations and argu- ments. However, natural theology is more than preaching to the converted as an internal confirmation of a Christian framework. By showing how a Christian framework may improve an otherwise non-theistic understanding of natural phenomena, one can argue that nature provides many open doors to a theistic framework. In this way, these arguments should challenge everyone, not only believers. ${ }^{67}$

It is well inside the scope of Natural Theology (NT) to look at some aspect of the natural world and thereby draw conclusions about some reality that extends beyond the natural world. This approach is non-reductionist. Instead of seeing nature as built from the ground up of mindless elementary constituents that come together through equally mindless forces, a revitalized natural theology may argue that a top-down purposiveness is central to a proper understanding of the world. Contemporary natural theologians point to the very existence of the world, the laws by which the world operates, the capacity of the world to organize itself, the fine-tuning and intelligibility 
of the world, and the unreasonable effectiveness of mathematics for comprehending the world as questions that nature raises but that also point beyond nature. The main results of our discussion is summarized in Table 1.

Alister McGrath qualifies NT in the following sense: Natural Theology is not about providing proof, it is about interpreting nature in light of the received Christian tradition. And when this interpretation makes sense of how we experience the world, there can be said to be 'a resonance' between this Christian framework and what is observed which gives the framework credibility. ${ }^{6}$

\section{Conclusion}

Darwinism has raised some challenging consequences for theology, and in questioning Darwinism, ID likewise has some important consequences for theology. This is not to say that ID is a theological initiative, any more than Darwinism is a theological initiative. ID conceived as a theory about the inherent limitations of natural causes to generate complexity, and the need for well-designed configuration in finely tuned initial conditions to overcome those limitations, is a scientific theory. Darwinism, conceived as a theory about how biological complexity has emerged in the history of life, is similarly a scientific theory. The laws, constants, and primordial initial conditions of nature present the flow of nature. These purely natural phenomena discovered in recent years show prospects of its being designed. Several cases of fine-tuned physics and biology are well-researched today and ready for the public arena.

Natural theologies were in their day first-rate instruments to educate people about the nature around us. For the church, this apologetic task is more neces- sary than ever before. Even though there is a huge difference between theological and scientific methodology, apologetic spokespersons should be willing to listen to scientists and be educated by them. There exists a common boundary between ID and NT, and the two may be considered close and interactive neighbors. At the boundary, questions are raised by science that cannot be answered by science alone. There are some obvious benefits to be gained from ID for contemporary theology. If theology wants to interact with secular culture, it should seek a better alliance with natural science. Here we have a position that places the burden of evidence on the shoulders of ID. The Christian philosopher William Lane Craig stated the fine-tuning argument in a 1998 debate with then atheist philosopher Antony Flew $^{69}$, and not long after this debate, Flew announced his conversion to a theistic worldview. 70

ID still needs to continue working on empirical criteria for identifying deliberately constructed products of intelligence. These criteria are necessary to make the explanations scientifically and philosophically legitimate. ID deserves attention in the scientific community as it competes with naturalistic macroevolution as a possible description for why things are the way they are. The basic notions behind ID is information-related. Within this setting, design promises to become an effective conceptual tool for investigating and understanding the natural world. The main motivation is to explore some fascinating possibilities for science and create room for new explorations.

Biologists need richer conceptual resources than the physical sciences have been able to generate. ${ }^{71}$ Yet ID has more work to do to establish itself better as a sustainable scientific theory, and ultima- 
tely a Design Science. Thus far, many theoretical and foundational concerns have tended to predominate. This may reflect the earliness of the hour and the need to clear the grounds before a shift of paradigms can take place. ID is a young scientific research program that wants to demonstrate its merits in the scientific world. Science has opened up to investigate several hypotheses about the nature of the physical and biological world that postulate design-like patterns at a funda- mental level. The results are of course most reliably answered retrospectively.

Nature is a mixed experience. ${ }^{72}$ It is not William Paley's happy world of everything in delicate balance and harmony. It is not the widely caricatured Darwinian world of struggle and survival of the fittest. Nature contains smart design and damaged design. Both science and theology need to come to terms with design as such and not dismiss it.

\section{Notes}

1 Ian G. Barbour, When Science Meets Religion: Enemies, Strangers, or Partners? (San Francisco: HarperOne, 2000).

2 Nathan J. Hallanger, "Ian G. Barbour" in The Blackwell Companion to Science and Christianity, eds. J.B. Stump and Alan G. Padgett (Malden, MA: Wiley-Blackwell, 2012), Chapter 52: 600-611. https://onlinelibrary.wiley.com/doi/pdf/10.1002/9781118241455.ch52

3 Del Ratzsch, "How Not to Critique Intelligent Design Theory” Ars Disputandi: The Online Journal for Philosophy of Religion, 5, 1-18 (2005).

4 Steinar Thorvaldsen \& Ola Hössjer "Using statistical methods to model the fine-tuning of molecular machines and systems" Journal of Theoretical Biology, vol. 501, 110352 (2020). Some parts of section 3 in the present paper are gained from this paper. http://dx.doi.org/10.1016/j.jtbi.2020.110352

5 Scott Mandelbrote, "The Uses of Natural Theology in Seventeenth-Century England", Science in Context, Vol 20 (3) (2007), pp. 451-480.

6 Steinar Thorvaldsen, "Kepler, Galileo, Newton and the Constructive Ideas of Modern Science" in Time, Reality and Transcendence in Rational Perspective, ed. Peter Øhrstrøm (Aalborg University Press, 2002), 11-38. Rodney Stark, For the Glory of God. How Monotheism Led to Reformations, Science, Witch-Hunts, and the End of Slavery (Princeton University Press, 2003).

7 Toby E. Huff, The Rise of Early Modern Science: Islam, China and the West (Cambridge: Cambridge University Press, 1993, 3rd Edition 2017).

Toby E. Huff, Intellectual Curiosity and the Scientific Revolution: A Global Perspective (Cambridge:

Cambridge University Press, 2010).

Peter Harrison, The Bible, Protestantism, and the Rise of Natural Science (Cambridge: Cambridge University Press, 2001)

Rodney Stark, For the Glory of God (Princeton: Princeton University Press, 2003).

8 John Lennox "Intelligent Design. Some Critical Reflections on the Current Debate” in Robert B. Steward (ed.), Intelligent Design. William A. Dembski \& Michael Ruse in Dialog (Fortress Press, 2007) pp. 179-195.

9 In recent years no less than 5 new editions of William Paley's classical book Natural Theology of 1802 have been published, i.e. Natural Theology, Oxford World's Classics, (Oxford: Oxford University Press, 2008)

10 Timothy Lenoir, "The Göttingen School and the development of transcendental Naturphilosophie in the Romantic Era” Stud Hist Biol, 5 (1981), 111-205.

https://web.stanford.edu/dept/HPST/TimLenoir/Publications/Lenoir_GottingenSchool.pdf Accessed 8.October 2018.

11 Ibid page xii.

12 Fernando Vidal \& Bernhard Kleeberg "Introduction: Knowledge, Belief, and the Impulse to Natural Theology" Science in Context, 20(3) (2007), pp.381-400.

13 Steinar Thorvaldsen \& Peter Øhrstrøm "Darwin's Perplexing Paradox: Intelligent Design in Nature" Perspectives in Biology and Medicine, 56(1) 2013, 78-98. https://muse.jhu.edu/article/509326/pdf

14 Psalm 19,2

15 Gillian Beer Darwin's Plots (Cambridge: University of Cambridge Press, 2000) 
16 T. Russell Hunter "Making a Theist out of Darwin: Asa Gray's Post-Darwinian Natural Theology"

Science \& Education, 21(7), (2012) 959-975.

https://link.springer.com/content/pdf/10.1007\%2Fs11191-011-9388-6.pdf

17 Lynn Barber, The heyday of natural history, (London: Jonathan Cape, 1980). See also Symposium on the Present Status of Natural Theology, The Journal of Philosophy. vol. 55(22), 1958, pp. 925-944.

18 William A. Dembski, Being as Communion: A Metaphysics of Information, p. 58, (Farnham: Ashgate, 2014).

19 Del Ratzsch, Nature, Design and Science (New York: State University of New York Press, 2001) p.5

20 Ibid p. 6.

21 Ibid p.9.

22 Steinar Thorvaldsen \& Peter Øhrstrøm "Darwin’s Perplexing Paradox: Intelligent Design in Nature.

Perspectives in Biology and Medicine" 56(1) 2013, 78-98.

23 Fred Hoyle \& Chandra Wickramasinghe, Evolution from Space, London, 1981/1984.

24 Steinar Thorvaldsen, The Unique Hoyle State of the Carbon Atom. Dialogo 2014, pp. 43 - 46.

https://munin.uit.no/handle/10037/11612

25 Fred Hoyle "The Universe - Past and Present Reflections, Engineering and Science, November 1981, p. 12. Also printed as an extended version" Annual Review of Astronomy and Astrophysics, vol. 20, 1982, pp. 1-35.

26 Owen Gingerich, God's Universe (Harvard: Harvard University Press, 2006) p.57.

27 Paul Davies The Goldilocks Enigma: Why Is the Universe Just Right for Life? (Bostron: Houghton Mifflin Harcourt, 2006) p. ix.

28 Brandon Carter, Large Number Coincidences and the Anthropic Principle in Cosmology. IAU Symposium 63: Confrontation of Cosmological Theories with Observational Data, (Dordrecht: Reidel, 1974) pp. 291-298.

29 Luke A. Barnes "The Fine-Tuning of the Universe for Intelligent Life. Publications of the Astronomical Society of Australia”, 29(4) 2012, pp. 529-564. https://doi.org/10.1071/AS12015. See also: Luke A. Barnes

"A Reasonable Little Question: A Formulation of the Fine-Tuning Argument" Ergo : an open access journal of philosophy. Vol.6, 2020, (20201021), pp.1220-1257. https://doi.org/10.3998/ergo.12405314.0006.042 and Fred C Adams, 2019, The degree of fine-tuning in our universe - and others. Physics reports, Vol.807, pp.1-111. https://doi.org/10.1016/j.physrep.2019.02.001

30 Geraint F. Lewis \& Luke A. Barnes: A Fortunate Universe: Life in a Finely Tuned Cosmos. (Cambridge: Cambridge University Press, 2016).

31 John D Barrow \& Frank J. Tipler, The Anthropic Cosmological Principle, (Oxford: Oxford University Press, 1988).

32 Martin Rees, Just Six Numbers: The Deep Forces that Shape the Universe. 1999.

33 Geraint F. Lewis \& Luke A. Barnes: A Fortunate Universe: Life in a Finely Tuned Cosmos. (Cambridge: Cambridge University Press, 2016) Forword p. xi

34 'Explore as much as we can': Nobel Prize winner Charles Townes on evolution, intelligent design, and the meaning of life. https://www.berkeley.edu/news/media/releases/2005/06/17_townes.shtml

35 Evgeny Epelbaum, Hermann Krebs, Timo A. Lähde, Dean Lee \& Ulf-G. Meißner "Viability of Carbon-Based Life as a Function of the Light Quark Mass" Physical Review Letters (2013) 110(11), 112502.

36 Peter R Wills "DNA as information" Phil. Trans. R. Soc. (2016) A.37420150417.

http://doi.org/10.1098/rsta.2015.0417

37 Bruce Alberts "The Cell as a Collection of Molecular Machines: Preparing the Next Generation of Molecular Biologists, Cell, vol. 92, (2018) pp. 291-294.

See also a special issue on Molecular Machines BioEssays, 2003 vol. 25(12).

38 Several scientists inspired ID, including professor A.E. Wilder-Smith: The Creation of Life. A Cybernetic Approach to Evolution, Harlow Shaw Publishers, 1970; Charles Thaxon: The Mystery of Life's Origin, Lewis and Stanley, 1984; Michael Denton: Evolution: A Theory in Crisis, Burnett Books, 1985.

39 Michel J. Behe, Darwin's Black Box: The Biochemical Challenge to Evolutio (New York: The Free Press, 1996), p.203

40 AMP: Adenosine Monophosphate is a nucleotide that is found in RNA and plays important role for intracellular signaling. Its delusive function is also used especially in diabetic products as bitterness suppressor.

41 Douglas D. Axe "Estimating the prevalence of protein sequences adopting functional enzyme folds" J Mol Biol. 341(5), 2004, pp.1295-1315. In his experiment, he used a functional sequence section of 150 amino acids of the antibiotic resistance protein called beta-lactamase. Axe has also given a popularized version of his argument in his book Undeniable: How Biology Confirms our Intuition that Life is Designed (San Fransisco: HarperOne, 2016)

42 Ibid p. 160. There is a helpful diagram of this in Undeniable on p. 162.

43 Del Ratzsch Nature, Design and Science (New York: State University of New York Press, 2001), p.60. 
44 Winston Ewert, Robert J. Marks II, and William A Dembski “On the Improbability of Algorithmic Specified Complexity” Southeastern Symposium on System Theory, IEEE, (Waco: Baylor Univ, 2013), pp. 68-70.

Winston Ewert, William A. Dembski, and Robert J. Marks II, “Algorithmic Specified Complexity” In Jonathan Bartlett (Ed.) et al., Engineering and the Ultimate: An Interdisciplinary Investigation of Order and Design in Nature and Craft (Blyth Institute Press, 2014) pp. 131-149.

45 Robert J. Marks II, William A. Dembski, and Winston Ewert Introduction to Evolutionary Informatics (New Yersy: World Scientific, 2017)

46 George D. Montanez “A Unified Model of Complex Specified information” Bio-complexity, 2018 (4), pp. 1-26. https://doi.org/10.5048/BIO-C.2018.4

47 William A. Dembski The Design Inference: Eliminating Chance Through Small Probabilities (Cambridge: Cambridge University Press, 1998) p. 8

48 Steve Fuller, Bradley Monton and Thomas Nagel, see ref. 63.

49 William A. Dembski, Being as Communion, p.128-129.

50 Douglas Walton “Abductive, presumptive and plausible arguments". Informal Logic, 21 (2) (2011): 141-169. Doi:10.22329/il.v21i2.2241

51 Vesa Palonen has published an online paper where he applies methods from Bayesian statistics to the fine-tuning argument. Bayesian methods are a special case of a more general type of abductive reasoning. Vesa Palonen, 2008, "Bayesian considerations on the multiverse explanation of cosmic fine-tuning", arXiv.org > physics > arXiv, https://arxiv.org/abs/0802.4013

52 Evgeny Epelbaum et al "Ab Initio Calculation of the Hoyle State” Phys. Rev. Lett. 106, 192501 (2011). https://doi-org.mime.uit.no/10.1103/PhysRevLett.106.192501

Timo A. Lähde et al., 2020, An update on fine-tunings in the triple-alpha process. Eur. Phys. J. A, 56 (3). https://doi.org/10.1140/epja/s10050-020-00093-0

53 Michael J. Behe, "Reply to my critics: A response to reviews of Darwin's Black Box: The Biochemical Challenge to Evolution” Biology and Philosophy 16 (2001):685-709.

Kenneth R. Miller "The flagellum unspun: the collapse of "irreducible complexity" In: Dembski WA and M Ruse, eds. Debating Design: From Darwin to DNA. (Cambridge: Cambridge University Press,2005) pp 81-97. William A. Dembski “Still Spinning Just Fine: A Response To Ken Miller: 1-12”: http://www.arn.org/docs2/news/wd_still_spinning.htm Accessed 6 November 2018.

M.J. Behe "Irreducible Complexity: Obstacle to Darwinian Evolution” in Dembski WA, Ruse M, eds. Debating Design: From Darwin to DNA. (Cambridge: Cambridge University Press, 2004) pp 352-370.

54 M.J. Pallen, \& N.J. Matzke "From the origin of species to the origin of bacterial flagella" Nature Reviews Microbiology, 4(10) (2006) pp. 784-790.

Michael Behe Darwin Devolves (San Fransisco: HarperOne, 2019) pp. 283-301.

55 Winston Ewert "Digital irreducible complexity: A survey of irreducible complexity in computer simulations” BIO-Complexity 2014 (1):1-10. http://bio-complexity.org/ojs/index.php/main/article/view/BIOC.2014.1 Accessed 8 November 2018.

56 William A. Dembski No free lunch: Why specified complexity cannot be purchased without intelligence. (Rowman \& Littlefield, 2002) chapter 5.10, pp. 289-310

57 Evandro Ferrada \& Andreas Wagner "Evolutionary Innovations and the Organization of Protein Functions in Genotype Space” PLOS ONE Vol 5(11) (2010( Article Number: e14172

58 Branko Kozulic \& Matti Leisola "Have Scientists Already Been Able to Surpass the Capabilities of Evolution?" viXra Biochemistry (2015) 1504.0130. http://vixra.org/bioch/1504 Accessed 8 November 2018. 59 Douglas D. Axe “The Case Against a Darwinian Origin of Protein Fold” BIO-Complexity, Vol 2010 (1), pp. 1-12. http://bio-complexity.org/ojs/index.php/main/article/view/BIO-C.2010.1 Accesses 8 November 2018

60 David T Dryden, Andrew R Thomson and John H White "How much of protein sequence space has been explored by life on Earth?” Journal of the Royal Society interface, Vol 5 (25) (2008) pp. 953-956.

61 Robert T. Pennock "Can't philosophers tell the difference between science and religion?: Demarcation revisited" Synthese, Vol. 178(2) (2011), pp. 177-206.

62 Maarten Boudry, Stefaan Blancke and Johan Braeckman, "Grist to the Mill of Anti-evolutionism: The Failed Strategy of Ruling the Supernatural Out of Science by Philosophical Fiat”, Science \& Education, 2012, Volume 21, Issue 8, pp 1151-1165

63 Steve Fuller, Dissent over Descent (Thriplow: Icon Books Ltd., 2008) Jeremy Shearmur, "Steve Fuller and Intelligent Design", Philosophy of the Social Sciences, 2010, 40(3) 433-445. DOI:

10.1177/0048393110368040 Bradley Monton, Seeking God in Science: An Atheist Defends Intelligent Design, 2009, Broadview Press Inc. Thomas Nagel, Mind and Cosmos: Why the Materialist Neo-Darwinian Conception of Nature is Almost Certainly False (Oxford: Oxford University Press, 2012) 
64 Williard Quine ”Naturalism; or, Living within one's means” Dialectica 49, 1995, pp. 251-262.

65 Thomas Kuhn, The Structure of Scientific Revolutions (Cham: Springer, 2015).

66 Franklin Harold The Way of the Cell (Oxford: Oxford University Press, 2001)

67 William Lane Craig \& J. P. Moreland (Eds.) The Blackwell Companion to Natural Theology (Oxford: Wiley-Blackwell, 2009)

68 Alister E. McGrath A Fine-Tuned Universe: The Quest for God in Science and Theology (Louisville, KY: Westminster John Knox, 2009) p. 218

69 Stan W. Wallace (Ed.), 2003, Does God Exist?: The Craig-Flew Debate. Routledge.

70 Antony Flew, There is a God. How the world's most notorious atheist changed his mind. (San Francisco: HarperOne, 2007) p. 32.

71 Del Ratzsch, "There is a place for intelligent design in the philosophy of biology: intelligent design in (philosophy of) biology: some legitimate roles" in Francisco José Ayala \& Robert Arp (eds.), Contemporary Debates in Philosophy of Biology (Oxford: Wiley-Blackwell, 2010) pp. 343-363.

72 Dietrich Bonhoeffer, Creation and Fall (Augsburg Fortress Publishers, 2007). 